\title{
Dissociation, reflexivity and habitus
}

Rafieian, S.; Davis, H.H.

\section{European Journal of Social Theory}

\author{
DOI: \\ $10.1177 / 1368431016646516$
}

Published: 01/11/2016

Peer reviewed version

Cyswllt i'r cyhoeddiad / Link to publication

Dyfyniad o'r fersiwn a gyhoeddwyd / Citation for published version (APA):

Rafieian, S., \& Davis, H. H. (2016). Dissociation, reflexivity and habitus. European Journal of Social Theory, 19(4), 556-573. https://doi.org/10.1177/1368431016646516

\footnotetext{
Hawliau Cyffredinol / General rights

Copyright and moral rights for the publications made accessible in the public portal are retained by the authors and/or other copyright owners and it is a condition of accessing publications that users recognise and abide by the legal requirements associated with these rights.

- Users may download and print one copy of any publication from the public portal for the purpose of private study or research.

- You may not further distribute the material or use it for any profit-making activity or commercial gain

- You may freely distribute the URL identifying the publication in the public portal ?
}

Take down policy

If you believe that this document breaches copyright please contact us providing details, and we will remove access to the work immediately and investigate your claim. 
Title: Dissociation, reflexivity and habitus

First Author: Shahram Rafieian

Affiliation: School of Social Sciences, Bangor University

Email: Rafieiansh@yahoo.com

Telephone: +44 (0) 7733721392

Fax: +44 (0) 1248382085

Address: 1 Maddison Road, Droylsden, Manchester, M14 5RY

Shahram Rafieian is a medical doctor graduated from Isfahan University of medical sciences, Iran. He also studied Masters of Psychology and a PhD in sociology and social policy at Bangor University, UK. His research interests are the role of body and emotions in the social life and developing an embodied relational social theory.

Second Author: Howard Davis

Affiliation: School of Social Sciences, Bangor University

Email: h.h.davis@Bangor.ac.uk

Telephone: +44 (0) 1248382123

Fax: $+44(0) 1248382085$

Address: Room 108, Neuadd Ogwen, School of Social Sciences, Bangor University, Gwynedd, LL57 2DG, UK

Howard Davis is Professor of Social Theory and Institutions in the School of Social Sciences, Bangor University. He studied sociology at Cambridge and Edinburgh before moving to Glasgow, where he was a founder member of the Glasgow University Media Group. He is currently a co-director of the Wales Institute of Social \& Economic Research, Data \& Methods (WISERD). His research interests include social theories of culture, the organization of creative work, civil society and questions of local, national and European identity. 


\section{Dissociation, reflexivity and habitus}

Many theorists, in their search for a better explanation of the dynamics of structure and agency, have expressed the need for a theory in which reflexivity and habitus are reconciled. In this paper we argue that a dissociative theory of mind can provide the essential framework in which habitual routines and reflexivity function in parallel. This is explored using the examples of athletic training and hypnosis, where the interplay between conscious and unconscious mechanisms is displayed. In both settings, there is evidence to show that conscious reflexiveness and intersubjective and unconscious automatic processes are necessary to reach the desired outcome. We conclude that a dissociative theory of mind can shed new light on the relationship between habitus and reflexivity.

Keywords: consciousness, dissociation, habitus, reflexivity, unconscious. 
Since the emergence of the discipline of sociology, theorists have struggled with a core problem, namely the relationship between structure and agency. In theorising the structure-agency relationship it is necessary to refer to the underlying mechanisms by which agents act in the society. In that context, theories of mind, subjectivity and consciousness have an important place. The habitus theory of Bourdieu $(1977,1990)$ builds on an understanding of practice in which the reproduction of structure is not the result of intentional and conscious actions of the people. Focusing on dispositions and the unconscious embodied mechanisms of transmission of sociocultural repertoire he considers the possibility of formation of habitus through agents' interactions with different fields (such as the academic or political fields) and the reproduction of both via this process (Swartz, 1997). Although the habitus theory has been influential, critics claim that it is deterministic and the agentic power of the individual is not adequately addressed (Crossley, 2001; Jenkins, 1982; King, 2000). The other important concept is reflexivity. In theories of reflexivity, the focus is on the individual's capacity for reflexive deliberation and conscious evaluation of the situation. Drawing on pragmatist theories, especially those in Peircean philosophy, Archer $(2000,2003)$ describes internal conversation as the most important mode of reflexivity. In her view, people use internal conversation to design projects to reach goals defined according to the ultimate concerns in their lives. Archer (2010b) rejects the need to give place to habitus or habit in her theories and believes that it is possible to develop an adequate theory of the structure-agency relationship without the need for the habitus concept. There are other theorists 
who believe that both habitus and reflexivity are necessary for a comprehensive formulation and who have made attempts to reconcile or hybridize them (Adams, 2006; Caetano, 2015; ElderVass, 2007; Mouzelis, 2007). In this paper our aim is to show the usefulness of the concept of dissociation for providing a better understanding of the reflexivity and habitus relationship. First, it is necessary to review the place of the concept of reflexivity.

\section{Theories of reflexivity in modern social theory}

American pragmatism is the important tradition in social philosophy in which the concept of reflexivity is well explored. The mode of reflexivity that pragmatists are particularly interested in is internal conversation. In fact, they assign a central role to inner speech in their theories of self but each exponent of pragmatism has their own conceptualization of this process. To Mead (1934) the self is evolved as a result of the dialogue between the ' $\mathrm{I}$ ', the self in the present moment, and the 'me' or the 'generalized other' which is the socialized aspect of the person that emerges through the person's interactions with the social world and is developed by internalization of the rules and norms of the society. To Peirce (1933: 421), the internal dialogue takes place between the 'I', the self in the present moment and the imagined self of the future or what he calls the 'you' (Wiley, 2006c). To develop a more comprehensive theory of self based on the process of internal conversation, Wiley (1994) has tried to merge the above theories and develop a triadic model of self development in which the self is formed in the process of the triadic dialogue between ' $\mathrm{I}$ ', 'Me' and 'you'. In this model, self development encompasses all interactions of the self at the present moment with the self which has emerged through the all past encounters with the society, and the imaginary and emerging self of the future (Rafieian, 2012). This synthesis has been influential in social theory and can be considered as a productive development. For example, in a 
special issue of the American Sociologist devoted to his works, commenting on Wiley's model of self, Barker (2005) states:

Each and every human being, according to Wiley, has a self that is a reality sui generis and that exists in time. The notion of self is not just a label or a name. The self is a sociological reality. We experience our individual selves as a continuous stream of consciousness consisting of our sense of our "me," "I" and "you." That is, at any one moment the social agent is aware of his or her "me-I-you." The semiotic self is the self understood within the Pragmatist perspective associated with Peirce and Mead. Mead contributed the theory of the "I" and the "me." Peirce implicitly contributed the "I" and the "you.” The "you” in Peirce’s theory of the self is not the other human being but our own "mirror image.” It is a future "looking glass self.” That "you” can also be discussed as a "Thou.” Each of us has a sense of our past, present and future in the present moment. The reality of the self is that awareness, including the notion that the "I" is double-sided. On the one hand the "I" keeps changing, but on the other hand the "I" becomes a kind of solid, inner core of the self, an inner gyroscope, our core identity (p.188).

In this pragmatist view, reflexivity is an ever present process which has a key role in self development. Similarly, Giddens $(1990,1991,1992)$ appreciates the fact the reflexivity is important for self formation as we continuously monitor our actions and behaviours. He also believes that there is a strong connection between modernity and reflexivity. To him, the key to reflexivity is the nature of knowledge in the ever changing societies of late modernity. People constantly re-evaluate their personal lives and give order to them based on the way that they narrate their personal stories. In modernity, with the loss of the salience of tradition, the self also loses its 
unquestioned and solid context to the extent that the self has become a 'reflexive project - a more or less continuous interrogation of past, present and future'(Giddens, 1992: 30).

Bourdieu (1977, 1990, 1998), as noted above, mainly emphasizes the unconscious and dispositional aspects of identity formation and uses the concepts of habitus and field to explain the ways in which social identity is constructed, cultural heritage is transmitted and structure is reproduced without the need for agents to have conscious aims. In his view, agents become reflexive only at times of crisis in which there is a mismatch between the field and habitus. Consequently, reflexivity does not have a fundamental place in his theories about the relationship between structure and agency (Bottero, 2010).

In contrast to Bourdieu, Archer considers reflexivity to be central in defining the structureagency relationship and she believes that reflexivity in the form of internal conversation is the mechanism which links agency to social structure. She does not see any need to give habitual and routine action a significant place in her formulation and believes that all attempts at hybridization or reconciliation of reflexivity and habit(us) have failed to provide an acceptable framework (Archer, 2010b).

The next step is to consider the relationship between habitus and reflexivity, and the advantages and inadequacies of different theories in relation to these concepts.

\section{Habitus, reflexivity and unconscious}

Archer's aim is to challenge theories that consider the human subject to be the product of social and structural forces and because of that, as Colapietro (2010) argues, she is fearful of reducing human agency to unconscious forces and the repetition of habitual actions. Critics of Archer suggest that her emphasis on reflexivity is too great and does not correspond to the conduct

of real agents in society. They state that ignoring habit and habitual action makes her theory of 
agency inadequate and the overemphasis on reflexivity results in a reductionist conceptualization (Akram, 2013).

On the other hand, critics of Bourdieu’s approach find him to be deterministic and prone to exaggerate the match between the habitus and field in daily life. The need for reflexive engagement is greater than he has allowed for in his theories (Bottero, 2010; Jenkins, 1982; King, 2000).

It can be judged from the above discussion that the core problem is the place of consciousness and the unconscious in theories about the structure- agency relationship. In fact Giddens (1979) has appreciated this need and states:

.. a conception of the unconscious is essential to social theory, even if the resultant schema I shall develop departs in some way from classical Freudian views. But the unconscious, of course, can only be explored in relation to the conscious: to the reflexive monitoring and rationalisation of conduct grounded in practical consciousness. We have a guard against a reductive theory of institutions in respect of the unconscious: that is, against a theory which, in seeking to connect the forms of social life to unconscious processes, fails to allow sufficient play to autonomous social forces. But we must also avoid a reductive theory of consciousness: that is, one which in emphasizing the role of the unconscious, is able to grasp the reflexive features of the action only as a pale cast of unconscious processes which really determine them (p.58).

While he has tried to incorporate the unconscious into his general theory, he is aware of the inadequacy of the Freudian approach (Giddens, 1984: 6-8) and in his formulation he borrows ideas from post-Freudian schools of psychoanalysis such as ego-psychology and object-relations theory (Groarke, 2002). In developing his approach he defines three basic elements in his 
conceptualisation of agency, namely: discursive consciousness; practical consciousness; and unconscious motives/cognition (Giddens, 1984: 7). The function of discursive consciousness is rationalisation of actions and it is about 'what agents are able to say about the conditions of their action' (Giddens, 1979: 57). Practical consciousness is knowledge related to dexterity and competencies in doing practical things, which he defines as 'tacit knowledge that is skilfully applied in the enactment of courses of conduct, but which the actor is not able to formulate discursively' (Giddens, 1979: 57).He describes unconscious motives/cognition as 'those forms of cognition and impulsion which are either wholly repressed from consciousness or appear only in distorted form’ (Giddens, 1984: 4-5).

The concept of practical consciousness in Giddens' theory that refers to the agent's competency in applying skills and performing practical tasks is essentially akin to Bourdieu's habitus and his idea about the possibility of the embodiment of culture and structure (Akram, 2013). In Giddens' view, reflexivity is the monitoring of social conduct, a capacity which he defines as 'characteristically involved in a continuous manner with the flow of day-to-day conduct in the contexts of social activity' but which he also appreciates 'operates only partly on a discursive level' (Giddens, 1984, p. xxii-xxiii). Although both Giddens and Bourdieu each has their particular version of reflexivity, they fail to conceptualize personal agency with effective causal power. This criticism needs closer scrutiny.

Both Bourdieu and Giddens state that their aim in theorising is to transcend the structure and agency dualism or the subjectivism and objectivism dichotomy. Archer (1988) coined the term 'central conflation' for the approach of these theorists and believes it to be mistaken. She defends the dualism of structure and agency and argues that when structure and agency are seen as 'mutually constitutive' it is impossible to analyse their 'reciprocal influences and impossible to 
separate the powers and properties of the practitioner from the forces and properties of the environment in which the practice is happening (Archer, 2000, p. 6). In other words, Archer believes the private internal world of the agent can function independently from structure and that internal conversation is the process through which it operates. Hence, for Archer, internal conversation is 'genuinely interior, ontologically subjective and causally efficacious '(Archer, 2003, p. 16) .

Sawyer (2002) describes the theoretical framework of Giddens as a process ontology in which individual and society are inseparable and compares it with Archer's emergentist theory in which the individual and society are distinct entities. He observes that although Giddens believes in the duality of individual and society, it does not solve the problem because it is a dualism that allows for analysis of interactions between the two. Commenting on the problem of this inseparability in structuration theory he states:

In structuration, there can be no individual experience that is not socially mediated; the self is purely sociological. Thus structuration rejects that action is motivated by internal intentions; intentions and reasons for actions are not properties of individuals but are ‘instantiated in that activity’. In sum, structuration cannot explain specific instances of human behaviour because inseparability rejects explanations both in terms of internal motivation and in terms of structural influences (p.290).

He also points to the fact that even those researchers who believe in the inseparability of individual and society at the theoretical level in practice take a dualistic approach in empirical research by analysing individual properties and treating them as characteristics independent of the forces and causal factors which derive from the sociocultural world of the agent (Sawyer, 2002) 
According to the above discussion, in the Archerian approach, reflexivity provides for the social agent a private internal subjective world which interacts with the sociocultural world. This private interior world is developed through interactions with others and, with maturation and especially with the formation of internal conversation, the individual can have internal deliberations without the help of others and reflexivity can take place independently from society. In this context, the important and critical function of reflexivity in the form of internal conversation is to address the agent's ultimate concerns and to design and refine their projects to reach their goals (Archer, 2003, pp. 40-41). In the following sections, we aim to re-examine different aspects of reflexivity in the light of the theory of dissociative mind and also explore the dynamic of reflexivity and habitual action in this context.

\section{Dissociative theory of mind}

Dissociation is a psychological phenomenon which is defined as 'separation of mental and experiential contents that would normally be connected'(Howell, 2005: 18). Dissociation can happen in normal life experiences, in which case it is described as normative dissociation (Butler, 2004, 2006) or in psychopathologies such as Dissociative Identity Disorder (DID) (Rafieian, 2011; Seligman and Kirmayer, 2008).Studies of dissociative experiences -irrespective of whether they are normative or pathological - have shown the quality of consciousness in humans and have revealed that at a particular moment in time, consciousness and attentional resources are directed towards internal or external objects disconnected from other entities in the internal and/or external world of the individual (Seligman and Kirmayer, 2008). In the dissociative theory of mind there is also an emphasis on the natural tendency of different psychological faculties of the individual to dissociate and an important role is given to the relational context and self-referential processes in the integration and organization of these different psychological components. From a 
developmental point of view, proper communication with primary caregivers and healthy attachment in the early years of life are critical for the development of self-referential mechanisms, and for the coherent and stable integration of psychological components. Insecure and disorganized attachment and problematic parent-infant interaction result in disruption in the development of the mechanisms needed to unify components of the self (Bucci, 2002; Carlson et al., 2009; Rafieian, 2011). Such individuals are predisposed to suffer from mental problems, especially dissociative problems, in later life. In this view, the sense of self is the product of interpersonal interactions between care givers and the infant. In the early stages, these interactions are in the form of non-linguistic and embodied communication which help the proper integration of various sensory data coming from various channels and the formation of the sense of unitary self (Liotti, 2006: 67). In later stages, with the development of language, the child internalizes the linguistic conversation with others and internal conversation is formed. This process takes place in the context of complex interactions of the individual with the social word in which dialogue with the others becomes internalized and results in the formation of inner speech. In fact this process, which was described by Vygotsky (1986), begins in early childhood when children speak aloud to themselves until gradually this activity is performed silently. With the development of inner speech and engagement of the individual with different social contexts, related thoughts, emotions, sensations and feelings are combined in each social context. With enough repetition of experience of that particular social context, they become organized in the form of a particular self state or personality. Different self states or personalities are connected with each other via self referential processes and internal conversation is the important tool for maintaining the dialogue between different self states. Normative dissociation is the necessary mechanism for a smooth shift from one self state to another (Bromberg, 1996; Rafieian, 2012). 
The dissociative theory of mind has two important consequences which are important for the problem of the relationship between habitus and reflexivity. First, it makes clear that it is possible for different psychological or psychomotor tasks to carry on together and, second, it provides a framework for the emergence of independent, interior and causally effective reflexivity. Here these two consequences are considered in more detail.

Taking the first consequence of dissociative theory of mind, we argue that the adaptive organization of the human cognitive and psychomotor system is such that it is possible for two or more processes to carry on at the same time and this allows the individual to engage in internal conversation while performing the routine activities of daily life. This mechanism is adaptive because such routine activities can occur with minimal need for attention and concentration and conscious resources can be devoted to internal conversation. This view of reflexivity in daily life is broader than the conceptualization of Giddens, as reflexivity in this sense - while it may include them is not only limited to monitoring or commenting on the actions and behaviour done by the agent. It may also take the form of conversation between the I-you-me described above and perform the task of maintenance and management of the self of the person as a whole. It means that this kind of reflexivity at a meta level deals with the big picture of an individual's life in which past experiences are a resource for the imagination of the future. It is not merely concerned with the activities that the person is engaged with at a specific point in time. This level of reflexivity which deals with agents' ultimate concerns and their personal projects is not explored by Giddens or other theorists who reject the dualism of subjectivity and objectivity. Archer believes that this lack of interest originates from their central conflationism (Archer, 2010a). She explains:

By definition, reflexive deliberation depends on maintaining a clear subjectiveobjective distinction. It can neither work nor be examined if there is any tendency to 
conflate the two by eliding the properties and powers pertaining to 'structure' and to 'agents'.... Deliberation consists in people evaluating their situations in the light of their concerns and evaluating their projects in the light of their circumstances. Any form of conflation fundamentally precludes examination of this interplay. It is submitted that the concept of 'institutionalized individualism' as the new structure of late modernity, could not be more conflationary in its clamping together of structure and agency (Archer, 2010a, p. 6).

In fact, the theoretical framework we are trying to develop provides the place for routine and habitual action which is missing in the Archerian theory. It is also compatible with Giddens' views about the necessity of routine life for providing security and confidence. Normally the agent performs the tasks of routine life with minimal need for attention and consciousness and is engaged in internal conversation in parallel. It is only in occasional situations of failure of a particular routine task that consciousness should be directed towards the task to fix it; otherwise the resources of consciousness will be devoted to more important activities such as internal conversation. But if the person is placed in a situation in which the environment is totally unfamiliar, conscious resources should be used for performing the tasks of daily life and not used for reflexive maintenance of the self. This results in failure to maintain a coherent self, threats to the integrity of identity, and the formation of anxiety.

As Emirbayer and Mische (1998) argue, agency is a temporally embedded process of social engagement in which components related to past, present and future have their own roles. The knowledge and skills coming from past experiences form the 'iterational' or habitual aspect. But there is also a projective capacity which is directed towards the future and certainly there is an aspect dealing with the present and the practical and evaluative capabilities of the agent. The 
parallel processing ability provided by the dissociative nature of mind permits both iterational and projective aspects to converge in the present moment and support the practical and evaluative capacities in the performance of daily tasks and social interactions.

The other important consequence of dissociative theory of mind is that it provides a framework for the formation of reflexivity in the form of internal dialogue. Regarding the nature of internal conversation, Archer finds the synthetic triadic pattern of me-I-You developed by Wiley helpful and adequate for encompassing different aspects of the self from past to future (Archer, 2010a). But drawing on the Vygotskyan and Bakhtinian conceptualizations, Fernyhough (1996: 51-53)explores the process of inner speech from a different perspective. He argues that from a developmental point of view, the healthy interaction of the child with caregivers and others results in the development of the dialogical mind. This results in the formation of higher mental functions which have certain characteristics. First of all, they incorporate different perspectives of reality which might be conflicting. These perspectives are not necessarily perceptual but could be ontological, axiological, or motivational. They are not necessary beliefs and are derived from the interaction of the child with others in a particular cultural system. The other notion is that the temporal order of external dialogue is not preserved in internal dialogue. As he explains: 'The dialogical nature of the higher mental functions stems from their ability to accommodate a "simultaneous unity of difference" rather than from any necessary resemblance to the "give and take” of conversation' (p.52). The dialogue in the mind is open-ended and continues throughout life and the individual is always ready to incorporate a new voice into his or her internal conversation. He claims that this openness of inner dialogue explains the proneness of the agent to be influenced by suggestions. He also observes that in its advanced form, the dialogical process of thinking is composed of abbreviated internal conversation or the interplay of different 
perspectives without the defined give and take structure of conversation. Development of the dialogical mind at this level results in the ability of the person to simultaneously adopt multiple orientations to reality (p. 52).

Emphasizing the critical role of care-givers in the development of a dialogic mind, Fernyhough argues that the ability to adopt multiple orientations toward reality develops at those times when care-givers collaborate in solving a problem and internalize a perspective on reality during external conversation. He uses the example of constructing a jigsaw puzzle in which the parent teaches the child that the result should be identical to the model and the child internalizes this fact and uses it in similar cases in her or his internal conversation. In this manner, by drawing the child's attention to different aspects of the problem, the child gradually acquires the skill of taking alternative perspectives and gains the ability to apply this method to solve a range of similar problems. In addition, Fernyhough provides evidence that supports the relationship between healthy attachment in early childhood and the proper development of a dialogic mind. This evidence shows that securely attached children perform better in tasks that require dialogic thinking, where it is necessary to hold two conflicting orientations to reality at the same time.

Based on qualitative empirical research Archer $(2003,2007)$ categorizes different modes of reflexivity and defines four different types of reflexivity, namely: communicative, autonomous, meta and fractured reflexivity. She defines these modes of reflexivity as follows. Communicative reflexivity is the mode of reflexivity in which 'internal conversations need to be confirmed and completed by others before they lead to action, thus fostering normative conventionalism'. Autonomous reflexivity is the mode of reflexivity in which 'internal conversations are selfcontained, leading directly to action and characterised by instrumental rationality. Meta-reflexivity is the mode of reflexivity in which 'internal conversations critically evaluate previous inner 
dialogues and are critical about effective action in society, in promoting value rational action'. Fractured reflexivity is the mode of reflexivity in which 'internal conversations cannot lead to purposeful courses of action and only intensify personal distress and disorientation, leading (temporarily) to "passive agents”'(Archer, 2010a, p. 9).

Commenting on her empirical research about the relationship between different modes of reflexivity and social mobility Archer explains that 'The present study makes its contribution less in relation to the social origins than to the social consequences of endorsing a particular mode of reflexivity as the dominant one, particularly in defining subjects' trajectories of social mobility’ (Archer, 2007, p. 97). This statement reveals her awareness of the fact that it is important to explore the social origins of different modes of reflexivity and one approach is to see them through the lens of developmental psychology and the concept of dialogic mind. From this perspective, the formation of each of these modes of reflexivity is the result of different levels of maturation of the dialogic mind and in the case of fractured reflexivity it could be said that the dialogic mind has failed to develop properly and there is inadequacy in the establishment of self-referential mechanisms. In other words, in each mode, the level of skills and the competency of the individual needed for elaboration of the problems is different. For example, engagement with meta-reflexivity in which the person 'critically evaluates previous inner dialogues' (Archer, 2010a, p. 9) requires higher mental ability compared with autonomous reflexivity. Also perhaps, autonomous reflexives are better able to use their normative dissociation to shift between different voices and maintain a successful and productive internal dialogue while in communicative reflexives this ability is not so well developed. In this context, the critical role of care-givers in helping the child to develop these skills and abilities should not be ignored. One area of research related to this notion is intergenerational transmission of trauma in which the traumatic experiences of the parents are 
transmitted to the children. This process has been explored by researchers in the fields of psychoanalysis (Bradfield, 2011, 2013; Brothers, 2014) and psychoanalytic sociology (Prager, 2003). In his research, Bradfield $(2011,2013)$ has shown empirically that traumatic experiences in the parents result in disorganised and traumatic attachment between the child and primary caregivers, which leads to disruption in the development of the dialogical self and improper formation of reflexive mechanisms.

The other related point worth considering in this context is the limits of internal conversation as a tool for being reflexive. Although internal conversation is important for mediation of agency, in some situations inner speech is not helpful and causes a problem. In fact, so called rumination, which is the intrusive and unwanted and uncontrolled repetition or intrusion of particular thoughts or voices is seen in psychopathologies. In a depressive patient, as NolenHoeksema (2008) and her colleagues show, rumination appears in the form 'of responding to distress that involves repetitively and passively focusing on symptoms of distress and on the possible causes and consequences of these symptoms' (p.400). This activity not only does not help the person to solve the problem, but can actually make the situation worse. In addition, it has been empirically shown that certain types of inner speech are associated with proneness to auditory hallucinations and dissociation is the mediatory mechanism in this process (Alderson-Day et al., 2014). As a consequence, the internal conversation can function as a tool for mediation of agency only if there is a healthy development of dialogical mind. Otherwise inner speech could be the producer and/or intensifier of psychopathology in the individual.

In the last section the relationship between internal conversation and practical consciousness will be explored. As mentioned, the concept of practical consciousness in Giddens' theory is similar to habitus in Bourdieu's theory. It is not possible to discursively express the 
embodied knowledge and practical skills needed for everyday life. This sort of knowledge is gained through practical engagement with the tasks of everyday life but the question arises: is reflexivity in the form of internal conversation independent from practical consciousness and, if not, what is the relationship between these two? Here we will try to address these questions.

\section{Habitus and internal conversation}

In the first instance, it is important to focus again on the developmental process of the internalization of language and the formation of internal conversation in early childhood. As Mead (1934: 156) states, in this period the child takes the role of others around and imitates the gestures of others in their role playing. At this primitive stage, the child takes the role of a person at one moment and speaks aloud in one character, and later takes another role and responds to the first character in the role of the other. Gradually, the child learns to have this kind of dialogue silently in his or her mind. Hence, internal conversation is an embodied process and it is not just voices talking in the head. New findings in psychology support this idea. The evidence shows that in internal dialogue, like external conversation, there is a close relationship between speech musculature and respiratory movements and the pattern of breathing changes with the changes in emotional state of the person and the quality of inner speech is changed in coordination with those variations (Chapell, 1994). The involvement of speech musculature is such that one of the methods of studying inner speech is to detect and measure the contractions in this group of muscles during this process (de Guerrero, 2005).

This view of internal conversation as an embodied process in which the voices are not disconnected from emotions, feeling and bodily experiences is also important for providing a better understanding of the relationship between internal conversation and habitus. Here we focus on this notion and try to clarify how the interaction occurs. 
Emphasizing the primacy of practice and embodiment, and the fact that thought and language are developed through embodied actions, Archer appreciates that there is a connection between discursive reflexivity and embodied practice (Archer, 2000, pp. 151-152). However, habitual action and its place is not well covered in her works nor has she developed a satisfactory theory to explain the interactions between these two. Giddens (1979: 57) considers consciousness in both its discursive and practical forms and the fact that reflexivity can be present at both levels of consciousness in the form of continuous monitoring of actions (using practical consciousness) and in the form of commenting on and expressing what the agent is doing at the level of discursive consciousness. In his view, although it is possible for agents to describe the conditions of their actions, the tacit knowledge and the embodied skills which belong to the category of practical consciousness cannot be formulated discursively. The problem with his theory is that he does not adequately explain the details of possible interactions between discursive and practical consciousness.

In their contribution, Noble and Watkins (2003) in a critical reading of Bourdieu's theory have tried to address this issue. They argue that the reason why habitus theory has been found to be deterministic is because Bourdieu has ignored the importance of consciousness. In a reaction to the cognitive bias of theories of his time he formulated a theory which overly relies on unconscious components of practice.

The metaphor that Bourdieu frequently used to describe habitus is 'feeling for the game' and he was particularly interested in sports and discussed the relationship between sports and social class. In Distinction (Bourdieu, 1984, p. 20) sport is considered to be a form of capital which has a symbolic function in defining people's social class. Taking this issue, Noble and Watkins have focused on the process of training in athletics and tried to clarify the function of consciousness in 
this context. They argue that to develop the player's feel for the game and before the individual becomes a masterful player there is a long process of training and a great deal of time devoted to practice. To substantiate his theory, Bourdieu just focuses on the experience of the expert player and overlooks the process of practice and the function of consciousness in discursive and practical forms in the process of learning and training. Regarding the interactions between coach and trainee, Bourdieu claims that the trainer speaks directly to the body (2000: 144) and believes that the body cannot not be thought by theoretical discourse (1977: 19). Noble and Watkins (2003: 528) criticize this view and state that it is a distorted picture of what happens in reality. As they observe, in sports training, the discursive dimension has an important role and the activities such as explanations, demonstrations and giving feedback all rely on discursive consciousness. In the process of learning a new technique, it is necessary to break it down into simple components and reconstruct it again to synthesise coherent and effective play. Theoretical discourse is needed for this sort of analysis. Also, the coach's feedback, which is mainly in the form of spoken words, is crucial in the course of adjustment and coordination of the player's body and its action during the game. Noble and Watkins accept Bourdieu's point that people do not think like philosophers in their everyday lives (Bourdieu, 1981) but they argue that this notion does not rule out the need for consciousness in practice. The fact that practice takes place primarily at a sub-conscious level does not mean that there is no interaction between practice and consciousness (2003, p.529). To further clarify this they focus on the complex nature of consciousness. They observe (p. 530) that consciousness is not a single and simple category and is present in different forms and qualities. In their view, Bourdieu's mistake is that he does not discriminate between calculation and consciousness in social practice and in his theory there is no discrimination between consciousness of action and consciousness in action as it is clarified in Giddens' theory in terms of the distinction between 
practical and discursive consciousness (1984: 4-7)or in Archer's theory in terms of the distinction between practical (or procedural) and discursive (or reflective) knowledge (2000: 162). From this point of view, they define different levels of awareness to explain the complex interactions between consciousness and embodied practice in sports training, namely agentic reflection, bodily attention and practical sense or automaticity. These are considered here briefly.

Based on Giddens' conceptualizations, Noble and Watkins define agentic reflection as the 'discursive practice in which we consider our behaviour and its principles, which involves the monitoring of conduct which can be brought to discourse' (p. 531). In the context of sports training this form of reflection is seen frequently in both forms of analysis and synthesis of actions in which past actions are reviewed and deconstructed into their components. Then to embody the revised version of these actions, they are reconstructed by imagination and new projects for actions are defined and designed based on these imaginations and projections of future actions. The second level, bodily attention, is placed between reflection and automaticity. This involves the players' ability to monitor their performance by feeling their actions. Interestingly, they point to the fact that at this level, mastering selective attention and control of shifting attention from one object to the other is crucial and internal dialogue is a tool that players use to regulate their attentional control (p. 532). The last level is practical sense or automaticity, the one that is emphasized by Bourdieu. Nobel and Watkins are in agreement with Bourdieu about the fact that automaticity is the cornerstone of achieving success in sports but they also find the other two levels of awareness necessary for reaching the level of automaticity and reject the possibility of obtaining this level without many hours of training in which discursive consciousness has a critical role.

Finally, they conclude by pointing to the importance of the web of intersubjectivity in the process of coaching and training. They argue that many athletes have admitted that their success 
would not have been possible without the help of their coach. In modern sport this process has become even more complex and there are teams of experts involved in the training of sportspeople. In this sense they argue against the theoretical position of Bourdieu in which the habitus and consciousness are opposed and define a framework in which discursive and practical consciousness are in complex interaction with each other.

Hypnosis is another quite different setting in which the interaction between habitus and consciousness in its different modalities can be studied. As Branier and her colleagues (2008) state, in hypnosis the hypnotist can produce dramatic experiences in the subject only by using words (p.141). One of the main characteristics of hypnotic phenomena is the sense of involuntariness. It means that while a hypnotic phenomenon is experienced, the individual has no sense of authorship over it and feels that the action or behaviour has happened by itself as a consequence of the suggestions given by the hypnotist. This automaticity is not only experienced during hypnosis, but also after hypnosis in response to post hypnotic suggestions. In this situation the individual experiences the automatic activation of a certain action or behaviour in response to a cue which has been described and assigned to that particular behaviour during hypnosis. In fact, in hypnosis the consciousness is directed as a result of suggestions in such a way that some actions, behaviours and/or physiological processes are facilitated which are not easily activated in normal daily life.

In term of the process of hypnosis and interactions between the hypnotist and subject, there is a widespread misbelief that the hypnotist imposes his or her will over the hypnotized. Challenging this idea, Musikantow (2011) argues that in the modern conceptualization of hypnosis the importance of the subject's role and the necessity of their agency have been realized and that it is a prevalent idea among hypnotists that 'all hypnosis is self hypnosis'. Musikantow claims that even this conceptualization is outmoded because it is linear and prefers an alternative view in 
which 'either the hypnotist is perceived as the causal agent or the client is perceived as the causal agent. What is missing from this description is what I refer to as an interactional view of human communication, with its conception of circular causality (p.84)'. In this view, the power is neither solely with therapist nor with the subject is but it shared between two. The construction of experience is the result of cooperation between both participants.

As seen in the similar context of sports training, there is close interaction between discursive and practical consciousness. As Noble and Watkins state, automaticity is central to sporting success and athletes have frequently described their experience of peak performance as automatic and felt to be involuntarily (p. 532-533). As discussed, a sense of involuntariness is also central to hypnotic phenomena and in fact the experience of automaticity is the key factor in making hypnosis a helpful tool for treatment and change of behaviour. As Noble and Watkins show, in sports training it is the close interaction between language, imagination and embodied knowledge of skills that makes the perfect automatic performance of sportspeople possible. Similarly, in the context of hypnosis, habit change and hypnotherapy, automaticity is experienced as a result of suggestions and imagination but to install the change and establish the desired outcome, practice is essential. This practice takes the form of internal conversation in which the person internalizes the suggestion received from the hypnotist and tries to reconstruct the experience which has been constructed in collaboration with the hypnotist in the hypnosis session.

Our aim in analysing and comparing hypnosis and sports training is to show the complex interactions of consciousness in its different modalities and embodied knowledge of skills which can be applied at an unconscious level. While it is beneficial for the purpose of theory making to define categories to explain social practice, it is also important to consider that these categories interact closely with each other and that sometimes the boundaries become blurred. 
As Dell (2010: 3) explains, it was the study of hypnosis that gave birth to the area of dissociation in psychology and the development of dissociative theories of mind. Historically, Pierre Janet (1859-1947) pioneered the development of dissociation theory which was further developed by Ernest Hilgard (1904-2001) in the form of neo-dissociation theory (Cardeña, 2014). Hypnosis can be experienced by any healthy person and is considered to be one the normative dissociative experiences (Butler \& Palesh, 2004).Today, researchers in the field of dissociation describe various positive dissociative experiences in which the common characteristics of dissociative phenomena such as absorption, alterations in the experience of self, and depersonalization are seen. Also there is a conceptual and phenomenological overlap between these and the state of flow in the psychology of creativity (Butler, 2006). Flow states as described by Csikszentmihalyi (1990) are enjoyable occasions in which there is a perfect match between skills and the task and the attention is fully absorbed in the activity, self-reflective mechanisms are halted and there is a distortion of time perception. The connection between dissociation and creativity has been explored in different areas such as fine arts (Pérez-Fabello and Campos, 2010) and musical creativity (Schubert, 2011). The paradoxical presence of automaticity and sense of involuntariness in the most creative moments of elite innovators in which consciousness is fully devoted to the ongoing task shows that there is a highly complex interaction between habitus and consciousness and none of them should be excluded from a comprehensive theory of social practice.

Considering the above discussion, it is possible now to evaluate current theories about the relationship between habitus and reflexivity. As critics have argued, the theories of both Archer and Bourdieu are inadequate as Archer does not appreciate the importance of habituality in her theory and Bourdieu devotes a minimal place to reflexivity. In Giddens’ theories, various modes 
of consciousness are considered and he has tried to develop a balanced view in which both reflexive and non-reflexive forms of human practice are covered. The problem is that there is central conflation in his theory which makes it impossible to analyse the interactions between agent and structure. Some theorists (Adams, 2006; Caetano, 2015; Mouzelis, 2007) have criticized Bourdieusian and Archerian approaches and called for a framework in which both reflexivity and habitus are present. Others have tried to take steps towards developing such theories. Sweetman (2003) has coined the term reflexive habitus to emphasize the fact that reflexivity is becoming more and more habitually used by an increasing number of people. Elder-Vass (2007)has tried to use the concept of emergence to reconcile habitus and reflexivity. The problem with these attempts is that none of them answers the question: how do habitus and reflexivity actually come together? As discussed, we have tried to show that the dissociative theory of mind can provide a framework in which habitus and reflexivity function together and we have explored the cognitive and psychophysical mechanisms underpinning this. This theory also helps us to understand the process by which a causally effective and independent form of reflexivity, namely internal dialogue, develops in the life course of the social agent.

\section{Conclusion}

Although with the emergence of modernity the day to day life of people is becoming more and more unpredictable and there is an increasing need for reflexivity, a basic level of routine and habituality is still needed to provide security and prevent disruptive anxiety. Consequently, any comprehensive theory of practice should provide room for both routine life and reflexivity.

As any reflexive process needs consciousness, to understand reflexivity there is a need for knowledge about consciousness. Because consciousness has different modalities, reflexivity also 
has different forms and can happen at different levels. The advanced form of reflexivity which is the language based process of internal conversation can be considered as the main mediator of social agency.

In this paper we have tried to shed some light on the relationships between habitus and reflexivity. With this aim, we proposed the dissociative theory of mind as a useful framework by which the place of reflexivity and habitus can be explained in social agency. Furthermore, we emphasized the developmental origins of reflexivity. Considering the fact that reflexivity is an emergent property it is important to consider the developmental context in which different modes of reflexivity are formed and to study them from this perspective.

Finally, the interactions between consciousness and embodied knowledge were explored using the two examples of sport training and hypnosis. This analysis shows that reflexivity and automaticity are interdependent and that automatic behaviour can be seen in even the most creative activities of human beings.

Adams M (2006) Hybridizing habitus and reflexivity: towards an understanding of contemporary identity? Sociology 40: 511-528.

Akram S (2013) Fully Unconscious and Prone to Habit: The Characteristics of Agency in the Structure and Agency Dialectic. Journal for the Theory of Social Behaviour 43: 45-65.

Alderson-Day B, McCarthy-Jones S, Bedford S, et al. (2014) Shot through with voices: Dissociation mediates the relationship between varieties of inner speech and auditory hallucination proneness. Consciousness and Cognition 27: 288-296.

Archer MS (1988) Culture and agency: The place of culture in social theory. Cambridge: Cambridge University Press.

Archer MS (2000) Being Human: the Problem of Agency. Cambridge: Cambridge University Press.

Archer MS (2003) Structure, Agency and the Internal Conversation. Cambridge: Cambridge University Press.

Archer MS (2007) Making our way through the world: Human reflexivity and social mobility. Cambridge: Cambridge University Press.

Archer MS (2010a) Reflexivity. Sociopedia.isa. Available from: http://www.sagepub.net/isa/resources/pdf/Reflexivity.pdf (accessed 12 May 2012).

Archer MS (2010b) Routine, Reflexivity, and Realism. Sociological Theory 28: 272-303. 
Barker JI (2005) The self as an internal dialogue: Mead, Blumer, Peirce, and Wiley. The American Sociologist 36: 75-84.

Barnier AJ, Dienes Z and Mitchell CJ (2008) How hypnosis happens: New cognitive theories of hypnotic responding. In: Nash MR and Branier AJ (eds), The Oxford handbook of hypnosis: Theory, research, and practice, New York: Oxford University Press, pp. 141-177.

Bottero W (2010) Intersubjectivity and Bourdieusian Approaches to 'Identity'. Cultural Sociology 4: 3-22.

Bourdieu P (1977) Outline of a Theory of Practice. Cambridge: Cambridge University Press.

Bourdieu P (1981) Men and Machines. In: Cicourel A V and Knorr-Cetina K (eds), Advances in social theory and methodology toward an integration of micro- and macro-sociologies, London: Routledge, pp. 304-317.

Bourdieu P (1984) Distinction. Canbridge MA: Harvard University Press.

Bourdieu P (1990) The Logic of Practice. Cambridge: Polity.

Bourdieu P (1998) Practical Reason: on the Theory of Action. Cambridge: Polity.

Bourdieu P (2000) Pascalian Meditations. Cambridge: Polity.

Bradfield B (2011) The dissociation of lived experience: A relational psychoanalytic analysis of the intergenerational transmission of trauma. International Journal of Psychoanalytic Self 6(4): 531-550.

Bradfield B (2013) The Intergenerational Transmission of Trauma as a Disruption of the Dialogical Self. Journal of Trauma \& Dissociation 14(4): 390-403.

Bromberg PM (1996) Standing in the spaces: The multiplicity of self and the psychoanalytic relationship. Contemporary Psychoanalysis 32: 509-536.

Brothers D (2014) Traumatic Attachments: Intergenerational Trauma, Dissociation, and the Analytic Relationship. International Journal of Psychoanalytic Self 9(1): 3-15.

Bucci W (2002) The referential process, consciousness, and the sense of self. Psychoanalytic Inquiry 22: 766-793.

Butler LD (2004) The Dissociations of Everyday Life. Journal of Trauma \& Dissociation 5: 111.

Butler LD (2006) Normative dissociation. Psychiatric Clinics of North America 29: 45-62.

Butler LD and Palesh O (2004) Spellbound: Dissociation in the movies. Journal of Trauma \& Dissociation 5: 61-87.

Caetano A (2015) Defining personal reflexivity: A critical reading of Archer's approach. European Journal of Social Theory 18(1): 60-75.

Cardeña E (2014) Hypnos and psyche: How hypnosis has contributed to the study of consciousness. Psychology of Consciousness: Theory, Research, and Practice 1: 123-138.

Carlson EA, Yates TM and Sroufe LA (2009) Development of dissociation and development of the self. In: Dell PF and O'Neil JA (eds), Dissociation and the Dissociative Disorders: DSMand Beyond., pp. 39-52.

Chapell MS (1994) Inner speech and respiration: toward a possible mechanism of stress reduction. Perceptual and Motor Skills 79: 803-811.

Colapietro V (2010) Cartesian privacy and Peircean interiority. In: Archer M (ed.), Conversations about Reflexivity, New York: Routledge, pp. 39-55.

Crossley N (2001) The phenomenological habitus and its construction. Theory and Society 30: 81120.

Csikszentmihalyi M (1990) Flow: The Psychology of Optimal Experience. New York: Harper \& Row. 
de Guerrero MCM (2005) Methodology of research on inner speech. In: Inner Speech-L2: Thinking Words in a Second Language, New York: Springer, pp. 89-118.

Dell PF (2010) Involuntariness in hypnotic responding and dissociative symptoms. Journal of Trauma \& Dissociation 11: 1-18.

Elder-Vass D (2007) Reconciling Archer and Bourdieu in an Emergentist Theory of Action. Sociological Theory 25: 325-346.

Emirbayer M and Mische A (1998) What is agency? American Journal of Sociology 103: 9621023.

Fernyhough C (1996) The dialogic mind: A dialogic approach to the higher mental functions. New Ideas in Psychology 14: 47-62.

Giddens A (1979) Central Problems in Social Theory: Action, Structure, and Contradictions in Social Analysis. London: Macmillan.

Giddens A (1984) The Constitution of Society: Outline of the Theory of Structuration. Cambridge: Polity.

Giddens A (1990) The Consequences of Modernity. Cambridge: Polity.

Giddens A (1991) Modernity and Self-Identity. Self and Society in the Modern Age. Cambridge: Polity.

Giddens A (1992) The Transformation of Intimacy. Cambridge: Polity.

Groarke S (2002) Psychoanalysis and structuration theory: The social logic of identity. Sociology 36(3): 559-576.

Howell EF (2005) The Dissociative Mind. Hillsdale NJ: The Analytic Press.

Jenkins R (1982) Pierre Bourdieu and the Reproduction of Determinism. Sociology 16: 270-281.

King A (2000) Thinking with Bourdieu against Bourdieu: A 'Practical' Critique of the Habitus. Sociological Theory 18: 417-433.

Liotti G (2006) A model of dissociation based on attachment theory and research. Journal of Trauma \& Dissociation 7: 55-73.

Mead GH (1934) Mind, self, and society from the standpoint of a social behaviorist (CW Morris, Ed.). Chicago: University of Chicago press.

Mouzelis N (2007) Habitus and reflexivity: Restructuring Bourdieu's theory of practice. Sociological Research Online 12(6): 9.

Musikantow R (2011) Thinking in circles: Power and responsibility in hypnosis. American Journal of Clinical Hypnosis, Taylor \& Francis 54(2): 83-85.

Noble G and Watkins M (2003) So, How did Bourdieu learn to play tennis? Habitus, consciousness and habituation. Cultural Studies 17: 520-538.

Nolen-Hoeksema S, Wisco BE and Lyubomirsky S (2008) Rethinking Rumination. Perspectives on Psychological Science 3: 400-424.

Peirce CS (1933) The Collected Papers of Charles Sanders Peirce. Cambridge MA: Harvard University Press.

Pérez-Fabello MJ and Campos A (2010) Dissociative experiences, creative imagination, and artistic production in students of Fine Arts. Thinking Skills and Creativity 6: 44-48.

Prager J (2003) Lost childhood, lost generations: the intergenerational transmission of trauma. Journal of Human Rights 2(2): 173-181.

Rafieian S (2011) Dissociative experiences in health and disease. Human Architecture 9: 89-110.

Rafieian S (2012) A biosemiotic approach to the problem of structure and agency. Biosemiotics 5 : 83-93.

Sawyer RK (2002) Unresolved Tensions in Sociocultural Theory: Analogies with Contemporary 
Sociological Debates. Culture \& Psychology 8: 283-305.

Schubert E (2011) Spreading activation and dissociation: A cognitive mechanism for creative processing in music. In: Hargreaves D, Miell D, and MacDonald R (eds), Musical Imaginations: Multidisciplinary perspectives on creativity, performance and perception: Multidisciplinary perspectives on creativity, performance and perception, Oxford: Oxford University Press, pp. 124-141.

Seligman R and Kirmayer LJ (2008) Dissociative experience and cultural neuroscience: narrative, metaphor and mechanism. Culture, Medicine and Psychiatry 32: 31-64.

Swartz D (1997) Habitus:a cultural theory of action. In: Culture and Power: The Sociology of Pierre Bourdieu, Chicago: University of Chicago Press, pp. 95-116.

Sweetman P (2003) Twenty-first century dis-ease? Habitual reflexivity or the reflexive habitus. Sociological Review 51(4): 528-549.

Vygotsky LS (1986) Thought and Language. Cambridge MA: MIT Press.

Wiley N (1994) The Semiotic Self. Chicago: University of Chicago Press.

Wiley N (2006) Pragmatism and the dialogical self. International Journal for Dialogical Science 1: $5-21$. 